\title{
"VAI JOGAR?" FATORES QUE INFLUENCIAM A PARTICIPAÇÃO DE ADOLESCENTES COM PARALISIA CEREBRAL NA EDUCAÇÃO FÍSICA ESCOLAR
}

\author{
"ARE YOU PLAYING?" FACTORS INFLUENCING PARTICIPATION OF \\ ADOLESCENTS WITH CEREBRAL PALSY IN SCHOOL PHYSICAL EDUCATION
}

\section{"VAS A JUGAR?" FACTORES QUE INFLUENCIAN LA PARTICIPACIÓN DE ADOLESCENTES CON PARÁLISIS CEREBRAL EN LA EDUCACIÓN FÍSICA ESCOLAR}

\section{Priscilla Rezende Pereira Figueiredo*, Marisa Cotta Mancini**, Marina De Brito Brandão**}

Palavras chave:

Educação Física e treinamento. Adolescente.

Paralisia cerebral. Inclusão educacional.

Resumo: O objetivo do estudo foi compreender fatores que influenciam a participação de adolescentes com paralisia cerebral (PC) na Educação Física Escolar. Dez adolescentes com PC foram entrevistados utilizando roteiro de entrevista semiestruturado, cujo conteúdo foi gravado, transcrito e submetido à Análise de Conteúdo. Três categorias e sete subcategorias emergiram dessa análise. Verificou-se que fatores ambientais (atitudinais e físicos) e pessoais influenciaram a participação. Especificamente, as atitudes de colegas, professores e monitores, bem como a disponibilidade de dispositivos de auxílio para marcha e a acessibilidade física da escola foram elementos importantes que impactaram, negativamente ou positivamente, a participação na Educação Física. Características pessoais, como medo de realizar as atividades e baixa ou alta percepção de autoeficácia, também influenciaram o engajamento dos adolescentes na Educação Física e devem ser consideradas por profissionais da Educação Física e reabilitação.

Keywords: Physical Education and Practice. Adolescent. Cerebral Palsy. Mainstreaming (Education).

Palabras clave: Educación Física y Entrenamiento. Adolescente. Parálisis Cerebral. Inclusión Educacional.
Abstract: The aim of the study was to understand factors influencing participation of adolescents with cerebral palsy (CP) in school Physical Education (PE). Semi-structured interviews were conducted with ten adolescents with CP. The interviews were recorded, transcribed and submitted to content analysis, resulting in three categories and seven subcategories. Environmental (attitudinal and physical) and personal factors influenced participation. Specifically, attitudes of peers, teachers and instructors, and availability of mobility devices and physical accessibility were important elements that influenced - negatively or positively - participation in PE. Personal characteristics such as fear of performing activities and low or high self-efficacy perception also influenced the engagement of adolescents in PE and should be considered by teachers and rehabilitation professionals.

Resumen: El objetivo del estudio es comprender factores que influencian la participación de adolescentes con parálisis cerebral (PC) en la Educación Física escolar. Diez adolescentes con PC fueron entrevistados utilizando un modelo de entrevista semiestructurado, cuyo contenido fue grabado, transcrito y sometido al análisis de contenido. Tres categorías y siete subcategorías surgieron de este análisis. Se verificó que factores ambientales (actitudinales y físicos) y personales influenciaron la participación. Específicamente, las actitudes de colegas, profesores y monitores, así como la disponibilidad de aparatos de ayuda para la marcha y la accesibilidad física de la escuela, fueron elementos importantes que han impactado, negativamente o positivamente, sobre la participación en la Educación Física. Características personales, como miedo a realizar las actividades y baja 0 alta percepción de autoeficacia, también influyeron en la participación de los adolescentes en la Educación Física y deben ser consideradas por profesionales de la Educación Física y rehabilitación.
*Associaccão Mineira de Reabilitação. Belo Horizonte, MG, Brasil. E-mail: pityrezende@yahoo.com.br

**Universidade Federal de Minas Gerais. Belo Horizonte, MG, Brasil. E-mail: marisacmancini@gmail.com; marinabbrandao@gmail.com

Recebido em: 28-01-2018 Aprovado em: 12-07-2018

DOI: https://doi.org/10.22456/1982-8918.79926 (c) (1) (8) Licence 


\section{INTRODUÇÃOO}

Os benefícios físicos e psicossociais da prática de atividade física na infância e adolescência estão extensamente documentados na literatura (BIDDLE; ASARE, 2011; FRITZ et al., 2016; JANSSEN; LEBLANC, 2010; KRIEMLER et al., 2011). Praticar atividades físicas regularmente pode auxiliar na prevenção de sobrepeso e obesidade (JANSSEN; LEBLANC, 2010), na melhora do condicionamento cardiorrespiratório (KRIEMLER et al., 2011), no fortalecimento muscular (FRITZ etal, 2016; JANSSEN; LEBLANC, 2010) e aumento da densidade óssea (FRITZ et al., 2016; JANSSEN; LEBLANC, 2010). Além disso, essa prática pode reduzir sintomas de depressão e ansiedade (BIDDLE; ASARE, 2011; JANSSEN; LEBLANC, 2010) e aumentar a autoestima dos indivíduos (BIDDLE; ASARE, 2011). Apesar disso, estima-se que a prevalência de inatividade física entre adolescentes brasileiros é superior a 50\% (BARBOSA FILHO, CAMPOS; LOPES, 2014; BARUFALDI et al., 2012;).

Em criançase adolescentes com paralisia cerebral (PC), a inatividadefísicaéuma situação alarmante, tendo em vista que os níveis de atividade física desses indivíduos são inferiores aos daqueles com desenvolvimento normal e abaixo do recomendado pelas diretrizes internacionais (CARLON et al., 2013). Nessa população, o nível inferior de atividade física pode contribuir para complicações secundárias, como baixos níveis de aptidão física, perda de habilidades funcionais, dor crônica, fadiga, osteoporose, obesidade e disfunções cardiovasculares (CARLON et al., 2013; FOWLER et al., 2007;). Tais complicações podem culminar em reduzidas qualidade e expectativa de vida (CARLON et al., 2013). Dessa forma, é recomendado que profissionais envolvidos no cuidado de indivíduos com PC encorajem e facilitem seu engajamento na prática de atividade física (CARLON et al., 2013; FOWLER et al., 2007).

As aulas de Educação Física na escola constituem oportunidade para o envolvimento da criança e do adolescente em atividades físicas (THOMASON; SCHEPP, 2011). Além dos benefícios físicos, essa disciplina tem papel importante na formação dos indivíduos ao oportunizar o desenvolvimento de habilidades sociais, como negociações interpessoais com pares, autoexpressão, respeito e valorização do próximo (BAILEY, 2006; MASURIER; CORBIN, 2006). Essas habilidades são especialmente importantes de serem desenvolvidas por crianças e adolescentes com PC, já que esses indivíduos frequentemente apresentam dificuldades relacionadas ao ajustamento social (e.g. estabelecimento de amizades e socialização), além de sofrerem isolamento e vitimização por parte de seus pares sem deficiência (NADEAU; TESSIER, 2006). Assim, a Educação Física pode contribuir para a saúde de indivíduos com PC no que diz respeito a aspectos físicos, sociais e cognitivos (BAILEY, 2006).

No Brasil, a introdução da Educação Física como componente curricular obrigatório da Educação Básica aconteceu na década de 1990 (CHICON, 2008). Entretanto, uma vez que os Programas de Educação Física gerais não conseguiam abarcar as necessidades específicas de pessoas com deficiência, houve o surgimento da Educação Física Adaptada, cujas atividades transcorriam em situações espaço-temporais distintas daquelas direcionadas às pessoas sem deficiências (CHICON, 2008). Apesar das contribuições da Educação Física Adaptada para a promoção da prática de atividade física e desportiva por crianças com deficiência, uma mudança na política de inclusão, desencadeada pela Declaração de Salamanca de 1994 (UNESCO, 1998) e pela Lei de Diretrizes e Bases da Educação (BRASIL, 1996), marcou o início de uma nova perspectiva em educação inclusiva. Nessa nova perspectiva, reconhece-se o direito de crianças e jovens com deficiência serem incluídos no sistema regular de ensino (UNESCO, 1998). Assim, as escolas regulares devem se engajar na acomodação de todas as crianças e 
jovens, no mesmo espaço e tempo, independentemente de suas condições físicas, intelectuais, sociais ou emocionais.

Apesar da legislação garantir ao aluno a oferta da Educação Física enquanto componente curricular da Educação Básica, a realidade da inclusão de alunos com deficiência nessa disciplina ainda se encontra distante dos parâmetros ideais (LEHNHARD et al., 2009). Sabe-se que o nível de comprometimento da função motora grossa ou possíveis dificuldades cognitivas podem restringir a participação dos indivíduos em situações de vida que envolvem atividades físicas (LAURUSCHKUS et al., 2013; PALISANO et al., 2009). Entretanto, é importante ressaltar que as práticas corporais não constituem a única forma de expressão do conteúdo das aulas de Educação Física. Numa perspectiva de formação ampliada, o papel da Educação Física envolve também a promoção do desenvolvimento sociocultural dos alunos enquanto cidadãos (BRASIL, 2006). Faz-se necessário, então, garantir a participação de todos os alunos, a despeito de sua aptidão física e desportiva, nas atividades propostas (BRASIL, 2006). Para tanto, compreender o conjunto de fatores que influenciam a participação de adolescentes com PC nas aulas de Educação Física poderá ajudar a nortear ações que promovam o envolvimento desses adolescentes nessa disciplina. O objetivo do presente estudo foi compreender os fatores contextuais (i.e., pessoais e ambientais) que influenciam a participação de adolescentes com PC nas aulas de Educação Física.

\section{PROCEDIMENTOS METODOLÓGICOS}

A compreensão sobre a participação de adolescentes com PC nas aulas de Educação Física demandou um método de pesquisa capaz de dar voz aos sujeitos, de forma que eles pudessem compartilhar as experiências vividas no contexto escolar. Dessa forma, foi conduzido um estudo qualitativo, de abordagem fenomenológica, cujos participantes foram dez adolescentes com diagnóstico de PC, de ambos os sexos, com idade entre 12 e 14 anos e classificados nos níveis I a IV do Sistema de Classificação da Função Motora Grossa (Gross Motor Function Classification System - GMFCS) (PALISANO et al., 1997) (Tabela 1).

Tabela 1 - Características descritivas dos adolescentes participantes

\begin{tabular}{llclcc}
\hline \multicolumn{1}{c}{ Nome Fictício } & Sexo & Idade (anos) & Tipo de Paralisia Cerebral & GMFCS & KBIT-2 \\
\hline Sofia & Feminino & 12 & Hemiparesia espástica & I & 85 \\
Luana & Feminino & 12 & Hemiparesia espástica & I & 115 \\
Gustavo & Masculino & 13 & Quadriparesia espástica & II & 71 \\
Guilherme & Masculino & 13 & Hemiparesia espástica & II & 81 \\
Marina & Feminino & 12 & Discinesia & II & 75 \\
Samuel & Masculino & 13 & Diparesia espástica & II & 98 \\
João & Masculino & 13 & Diparesia espástica & III & 131 \\
Ana & Feminino & 13 & Quadriparesia espástica & IV & 97 \\
Gabriela & Feminino & 12 & Quadriparesia espástica & IV & 96 \\
Lucas & Masculino & 13 & Quadriparesia espástica & IV & 89 \\
\hline
\end{tabular}

Fonte: os autores

Legenda: GMFCS = Sistema de Classificação da Função Motora Grossa [Nível I: deambulação sesm restrições; Nível II: limitações para caminhar longas distâncias e déficit de equilíbrio; Nível III: uso de dispositivos de auxílio para marcha, como andadores, muletas ou bengalas; Nível IV: locomoção por meio de cadeira de rodas manual ou motorizada; Nível V: mobilidade bastante limitada mesmo com o uso de tecnologia assistiva]. KBIT-2 = Kaufman Brief Intelligence Test [Pontuação igual ou maior que 85 indica Quociente de Inteligência (QI) no Domínio de Conhecimento Verbal do teste dentro da média de pontuação com desenvolvimento normal na mesma faixa etária; * pontuação entre 70 e 84 indica QI abaixo da média]. 
A maioria dos adolescentes participantes do estudo apresentava habilidades cognitivas condizentes com a população com desenvolvimento normal na mesma faixa etária (i.e., Quociente de Inteligência igual ou maior que 85 pontos na subescala de Conhecimento Verbal do Kaufman Brief Intelligence Test - KBIT-2) (KAUFMAN; KAUFMAN, 2004); apenas três participantes estavam abaixo da média (Tabela 1). Todos os adolescentes cursavam o ensino fundamental em escolas regulares da rede pública de Belo Horizonte.

Os adolescentes foram propositalmente recrutados na Associação Mineira de Reabilitação e, juntamente com seus pais, foram esclarecidos acerca dos objetivos e procedimentos da pesquisa. Aqueles que concordaram com a participação voluntária no estudo assinaram o Termo de Assentimento e o Termo de Consentimento Livre e Esclarecido, respectivamente. $O$ estudo foi aprovado pelo Comitê de Ética em Pesquisa da Faculdade de Ciências Médicas de Minas Gerais (CAAE, n.25674313.1.0000.5134).

A obtenção dos dados ocorreu por meio de entrevista semiestruturada (SILVA et al., 2006) conduzida individualmente com cada adolescente pela primeira autora do estudo (fisioterapeuta recém-ingressada na instituição, que não conhecia os adolescentes anteriormente e com conhecimento acerca do método qualitativo). 0 roteiro da entrevista foi construído por duas pesquisadoras (a entrevistadora e outra pesquisadora com conhecimento sobre o método qualitativo) com o objetivo de identificar, sob a perspectiva dos adolescentes com PC, como ocorria a participação na Educação Física Escolar. A entrevista abordava a percepção do adolescente sobre sua participação nas atividades da Educação Física; pontos positivos, dificuldades ou incômodos vivenciados; e relacionamento com os colegas e professores durante as aulas. As entrevistas ocorreram na Associação Mineira de Reabilitação, em local que conferia aos adolescentes privacidade para que eles pudessem expressar suas opiniões livremente. A média de duração das entrevistas foi de 14,3 minutos e o conteúdo (áudio) foi gravado com gravador digital Sony icd-bx800 e posteriormente transcrito na íntegra por um segundo pesquisador.

O método de amostragem por saturação foi utilizado para definir o número total de participantes do estudo. De acordo com esse método, quando as informações fornecidas por novos entrevistados passam a se repetir com frequência, pouco acrescentando aos dados já coletados, não há necessidade de inclusão de novos participantes (FONTANELLA; RICAS; TURATO, 2008). Para tanto, cada entrevista foi transcrita logo após ser finalizada e feita leitura flutuante por duas pesquisadoras. Quando se observou que não havia acréscimo de novas informações, foi encerrada a coleta de dados.

Para análise dos dados foi realizada Análise de Conteúdo, que possibilita a compreensão do pensamento dos participantes através do conteúdo expresso no texto das entrevistas (HAGUETTE, 2005). Essa análise foi composta por três etapas: (1) pré-análise do material, na qual duas pesquisadoras independentes leram o conteúdo das entrevistas repetidas vezes no intuito de formular hipóteses e indicadores, (2) exploração do material, na qual as mesmas pesquisadoras, de maneira independente, codificaram os dados em unidades através da identificação de falas dos entrevistados que carregavam um mesmo significado central e (3) tratamento e interpretação dos dados, etapa na qual as pesquisadoras condensaram as unidades semelhantes e separaram aquelas diferentes de forma a categorizar os elementos textuais em categorias e subcategorias (HAGUETTE, 2005). O estabelecimento das categorias e subcategorias foi realizado após um processo de reflexão e discussão entre os pesquisadores envolvidos na análise. 


\section{RESULTADOS}

A partir da análise de conteúdo foram identificadas três categorias: (1) "Não tem como eu participar...", que reúne os fatores percebidos pelos adolescentes como elementos que restringem sua participação nas aulas de Educação Física; (2) "Eu participo quando...", que engloba aspectos percebidos pelos adolescentes como facilitadores da participação; e (3) "Facilitaria se...", que abrange as sugestões mencionadas para promoção da participação. As categorias e subcategorias estão apresentadas no Quadro1. Os nomes dos participantes são fictícios para garantir o anonimato.

Quadro 1 - Categorias e subcategorias de análise

\begin{tabular}{|c|c|c|}
\hline "Não tem como eu participar..." & "Eu participo quando..." & "Facilitaria se..." \\
\hline $\begin{array}{l}\text { "Ah, essa fracote não vai } \\
\text { aguentar!" }\end{array}$ & $\begin{array}{l}\text { "Ele me incentiva, ele me motiva, } \\
\text { ele me anima!" }\end{array}$ & \multirow[t]{3}{*}{$\begin{array}{l}\text { "Se elas não tivessem preconceito, } \\
\text { né?" }\end{array}$} \\
\hline $\begin{array}{l}\text { "O problema é que tem monte de } \\
\text { buraco lá na escola!" }\end{array}$ & $\begin{array}{l}\text { "Com o andador eu faço um monte } \\
\text { de coisa" }\end{array}$ & \\
\hline $\begin{array}{l}\text { "Por causa do meu medo não tem } \\
\text { como eu participar" }\end{array}$ & $\begin{array}{l}\text { "O importante não é ganhar, é } \\
\text { tentar" }\end{array}$ & \\
\hline
\end{tabular}

Fonte: Os autores

\section{1 "Não tem como eu participar..."}

Ao refletirem sobre o atual nível de participação na Educação Física, alguns adolescentes afirmaram não participar dessa atividade: "Ah, eu não faço Educação Física, eu fico sentado lá na arquibancada que tem do lado da quadra" (Samuel). Ou ter sua participação restrita em determinadas atividades: "[...] os jogos que tem que jogar a bola muito alto com o braço eu não, eu não participo" (Ana). Quando não estão participando das aulas, os adolescentes relataram que permanecem assistindo os colegas realizarem as atividades "[...] aí eu tinha que ficar sentada assim, olhando os meninos fazer, se divertir..." (Luana), conversando com o monitor de inclusão ou colegas "[...] a gente fica conversando lá... mas pelo menos a gente está presente na aula, pelo menos a gente não perde ponto" (Gabriela) ou realizando outras atividades (e.g. jogos de cartas, leitura de livros) "[...] É por isso que eu só jogo UNO, aqueles jogos com meus colegas" (Lucas); "[...] aí eu fico na biblioteca lendo livros" (Luana). Os elementos mencionados pelos entrevistados que sugerem barreiras para participação foram agrupados nas subcategorias abaixo.

\subsection{1 "Ah, essa fracote não vai aguentar!"}

Algumas atitudes adotadas pelas pessoas que compõe 0 universo escolar dos adolescentes, como colegas de classe, professores de Educação Física, monitores e diretores, foram apontadas pelos adolescentes como barreiras à participação na Educação Física. Com relação aos colegas, foram reportadas atitudes que demonstravam indiferença "[...] eles (colegas) participam de tudo, então eles nem ligam muito pra quem não faz. Eles estão participando, então pra eles tanto faz" (Ana), baixa receptividade "[...] como o esporte tem que ser mais lento e tomar mais cuidado comigo, aí, alguns meninos eu escutei eles falando: 'Ah 
não, ele vai entrar?'” (João) e hostilidade "Aí eu tava jogando lá e ela (falou): 'Ah, essa fracote não vai aguentar! Essa metida, essa que todo mundo entrega tudo na mão, essa problemática, tem problema na perna e ainda tem problema no cérebro"' (Luana). Além disso, o conteúdo das entrevistas sugere que as atitudes negativas dos colegas ficam evidentes em atividades com alta demanda motora, como correr e arremessar bola com rapidez. "Em atividades que eu tenho que correr, pegar a bola e jogar rápido, às vezes eu tenho a impressão que eles (os colegas) acham que eu atrapalho, porque eles ficam falando pra eu passar a bola, falando que eu tenho medo da bola, que eu estou atrasando a brincadeira" (Ana).

Com relação às atitudes dos professores, os entrevistados mencionaram comportamentos que demonstraram indiferença: "A minha professora, ela não se importava muito [...]" (Ana). Exclusão: "A professora me põe pra jogar totó na mesa. É meio chato porque ninguém está jogando totó lá, só eu! Eu me sinto meio excluída" (Ana). Superproteção: "[...] Eu queria entrar, só que a professora falou que não era pra eu fazer Educação Física e que eu não precisava entrar na água não, [...] depois nós se machuca, que você é frágil, que você é isso, que você é aquilo [...]" (João). Falta de credibilidade no potencial do aluno: "Ela (a professora) não deixava eu participar muito porque ela não sabia... ela num botava fé em mim, ela não acreditava que eu era capaz de fazer" (Luana). E acomodação: "Só que esse ano tá meio ruim! Porque minha professora, eu não sei se é por causa que ela quer evitar o trabalho dela ou ela quer evitar o meu trabalho... ela falou que é pra eu ficar lá em cima, num é nem pra eu descer pra quadra, num precisa nem fazer Educação Física que ela ia me dar os pontos sem eu fazer nada" (João). Além disso, o fato de o(a) professor(a) não adaptar as atividades para o nível de habilidades do adolescente pode também dificultar a participação de alunos com PC: "Eu não sou muito de participar, sabe? A professora só faz brincadeira de correr..." (Lucas).

Com relação ao monitor, a ausência desse profissional ou a falta de colaboração dele foram consideradas barreiras que restringiram a participação dos adolescentes: "[...] às vezes minha monitora tem que ir ao médico no horário da Educação Física..." (Luana); "Os acompanhantes quererem também participar, porque às vezes eles sentam lá e nem... É chato!" (Ana).

Atitude do(a) diretor(a) da escola também pareceu exercer influência sobre a participação de adolescentes com PC na Educação Física. Posturas adotadas por esse dirigente que demonstram consentimento com a falta de preparo do professor impactaram negativamente a participação desses alunos nas aulas de Educação Física: "A minha diretora veio com uma desculpa falando que as professoras não sabiam fazer esporte adaptado" (João); também evidenciaram superproteção de alunos com deficiência "[...] ela também falou que eu não precisava fazer nada, que aí eu cansava, que era muito ruim porque se com o cansaço eu acabasse machucando" (João).

\subsection{2 "O problema é que tem um monte de buraco lá na escola!"}

Características do contexto físico relacionadas à irregularidade do terreno onde as aulas de Educação Física são realizadas apareceram no relato dos entrevistados como fatores que restringiram a participação: "Por causa desses buracos, tem momentos que eu quero correr e não posso. Quando você vai andar para chutar uma bola, por exemplo, a rodinha agarra no buraco, aí você tem que fazer vários movimentos pra tirar essa rodinha" (Lucas). 


\subsection{3 "Por causa do meu medo não tem como eu participar"}

Características pessoais, como atitudes e sentimentos dos adolescentes com PC frente às aulas de Educação Física também foram mencionadas nas entrevistas. 0 medo "[...] mas por causa do meu medo não tem como eu participar" (Lucas); introspecção "[...] eu não gosto muito de ficar brincando com os meus colegas. Eu sou mais quietinha" (Marina); preguiça "[...] às vezes eu fico com preguiça também de sair lá do meu lugarzinho, quentinho" (Samuel); baixa percepção de autoeficácia "[...] se eu fosse jogar bola eu ia cansar muito mais rápido que os outros, né? Por isso que eu também não jogo tanto bola" (Samuel); comparação das próprias habilidades com as dos colegas sem deficiência "[...] eu fico olhando os meninos jogar bola e fico pensando assim: Nó, o dia que eu aprender a jogar bola desse jeito, Nossa Senhora, todo mundo vai ver! Quando eu aprender a jogar bola desse jeito, todo mundo vai ver como é que é!" (Samuel); e desânimo "Também tem vez que você está desanimado" (Lucas) foram fatores pessoais presentes na fala dos entrevistados que parecem restringir a participação.

\section{2 "Eu participo quando..."}

Os participantes do estudo também apontaram elementos que facilitaram a participação nas aulas de Educação Física, como atitudes de membros do contexto escolar, uso de equipamentos de deambulação e características próprias dos adolescentes. Esses elementos são apresentados nas subcategorias a seguir.

\subsection{1 "Ele me incentiva, ele me motiva, ele me anima!"}

Atitudes de incentivo/motivação por parte dos colegas de classe "[...] tem uma menina na minha sala que ela, tipo assim, ela fala: "Parabéns, Sofia!" (Sofia); demonstrações de amizade "Os novos colegas acham legal eu participar, eles são meus amigos mesmo, eles gostam de mim" (Luana); e disponibilização de auxílio na atividade: "Porque dependendo eu não alcanço a rede! [...] aí eu peço pra alguma colega minha me ajudar, senão eu não consigo! Elas sacam a bola lá pra mim do outro lado da rede!" (Gabriela) parecem facilitar a participação de adolescentes com PC nas aulas de Educação Física.

O(a) professor(a) de Educação Física e o(a) monitor(a) também podem facilitar a participação dos adolescentes do estudo quando demonstram interesse em incluí-los nas atividades (1) por meio de incentivo: "[...] agora a professora está conversando comigo, falando assim que eu não tenho que ouvir elas (colegas), que eu que tenho que saber das coisas. O que ajudou foi a professora conversar comigo" (Sofia); "Ele (o monitor) me incentiva, ele me motiva, ele me anima!" (Lucas); (2) ao realizarem adaptações das atividades: "[...] ela (professora) olhou tudo no computador e descobriu maneiras de todos os esportes fazer um jeito adaptado. Eu gostei muito porque ela foi a primeira professora que fez essa ideia de adaptar os esportes, de dar um jeito pra eu poder entrar em tudo" (João); (3) e ao disponibilizarem auxílio: "Minha professora me ajuda a levantar..." (Gustavo) "[...] A minha acompanhante me ajuda, porque tem umas atividades que são muito difíceis, tipo queimada que eu tenho que correr e pegar a bola. [...] alguém tem que pegar a bola pra mim e jogar enquanto eu corro" (Ana). 


\subsection{2 "Com o andador eu faço um monte de coisa"}

O papel facilitador de dispositivos de auxílio para marcha foi evidenciado pelos adolescentes: "Mas só dá pra participar quando eu estou com o andador. Com o andador eu jogo bola, faço um monte de coisa" (Lucas); embora pareça ser um fator que depende da estrutura física do ambiente: "[...] mas só que o problema é que tem um monte de buraco lá na escola! Aí num dá... Por causa desses buracos, tem momentos que eu quero correr e não posso" (Lucas).

\subsection{3 "O importante não é ganhar, é tentar"}

A alta percepção de autoeficácia e autoestima "[...] me considero capaz, porque eu sou capaz mesmo. E mesmo que eu erre, ou perca, tem uma frase que eu sempre uso, o importante não é ganhar é tentar e quem tenta é que vence" (Luana), bem como a busca por ajuda "[...] às vezes é muito alto, aí eu peço pra um colega meu me ajudar! Aí ele segura na minha mão e eu taco a bola" (Gabriela) são atitudes pessoais que favorecem a participação dos adolescentes com PC nas aulas de Educação Física.

\section{3 "Facilitaria se..."}

Durante as entrevistas, os adolescentes expuseram seus pensamentos a respeito de mudanças relativas ao contexto atitudinal que poderiam ser implementadas no ambiente escolar, no sentido de favorecer sua participação nas aulas de Educação Física.

\subsection{1 "Se elas não tivessem preconceito, né?"}

Com relação às atitudes dos colegas, os adolescentes mencionaram que a eliminação de palavras que demonstram falta de crença em suas capacidades "As meninas parar de falar que eu não consigo, que eu não sou capaz" (Sofia) e a erradicação do preconceito "Se elas (colegas) não tivessem preconceito, né? Isso facilitaria muito" (Luana) poderiam facilitar a participação. Com relação ao professor de Educação Física, os adolescentes sugeriram maior engajamento desse profissional na adaptação das atividades: "Se eu fosse o professor, eu adaptaria mais os esportes, deixaria mais fácil, mesmo que na sua sala não tivesse nenhum deficiente. Já deixaria esportes preparados pra deficientes, tipo assim guardados caso precisasse" (João) e na graduação da sua complexidade de acordo com as habilidades de todos os adolescentes "Eu colocaria atividades mais lentas pra eu poder participar melhor, até para os outros poderem participar também que num é só eu, eles ficam meio excluídos também" (Ana).

\section{DISCUSSÃo}

O presente estudo identificou fatores contextuais - ambientais e pessoais - que influenciaram a participação dos adolescentes com PC nas aulas de Educação Física Escolar. De acordo com o conteúdo das entrevistas, tais fatores relacionaram-se aos contextos atitudinal (atitudes de colegas, professores e monitores), físico (acessibilidade arquitetônica e dispositivos de mobilidade) e pessoal (atitudes e comportamento dos adolescentes). 
Em relação ao contexto atitudinal, é interessante observar que o comportamento dos colegas, professores e monitores pode se apresentar como facilitador ou barreira à participação. Atitudes que demonstram incentivo, amizade, disponibilização de auxílio e adaptação das atividades encorajaram a participação. Por outro lado, atitudes que evidenciaram indiferença, baixa receptividade, exclusão e superproteção dificultaram o engajamento de adolescentes com PC na Educação Física. Outros autores já sinalizaram a influência do contexto atitudinal na participação de indivíduos com deficiências no ambiente escolar (CHICON; MENDES; SÁ; 2011; HILDERLEY; RHIND, 2012; LAURUSCHKUS; NORDMARK; HALLSTRÖM, 2014; LIMA; SILVA, 2009). Lauruschkus, Nordmark e Hallström (2014) enfatizaram que a ausência de amigos e a exclusão/segregação são vistas como barreiras para o engajamento de crianças suecas com PC em atividades físicas. Similarmente, no estudo de Hilderley e Rhind (2012), adolescentes americanos com PC apontaram a falta de interesse dos colegas em envolvêlos nas atividades da Educação Física e a superproteção por parte dos professores como fatores que impactaram negativamente sua participação. Situações similares de segregação e superproteção durante as aulas de Educação Física também já foram reportadas por autores de estudo envolvendo adolescentes brasileiros com outras deficiências (i.e., baixa visão e Síndrome de Down) (CHICON; MENDES; SÁ; 2011). Os autores sugerem que esse tipo de atitude repercute negativamente no encorajamento do grupo para perceber, respeitar e integrar os pares com deficiência, tornando-se grande empecilho para o processo de inclusão (CHICON; MENDES; SÁ; 2011). Em conjunto, os resultados do presente estudo e a literatura acerca da influência de fatores contextuais na participação ilustram os possíveis papéis protagonizados por colegas e professores no contexto escolar: se por um lado algumas atitudes desses indivíduos podem facilitar o engajamento de alunos com PC nas aulas de Educação Física, por outro lado, esses indivíduos podem adotar atitudes que culminam na restrição de participação de adolescentes com deficiência.

A influência do professor de Educação Física na participação dos adolescentes com PC foi mencionada pelos entrevistados. De acordo com os relatos, não é incomum que o professor atribua atividades alternativas aos alunos com deficiência (e.g., jogo com bola ou jogo de tabuleiro sozinho ou com o monitor) ou dispense esses alunos das aulas sem consequências acadêmicas (i.e., perda de pontos ou frequência), situação referida como "dispensa oculta" por Chicon, Mendes e Sá (2011, p.194). Nessas situações, embora os adolescentes com PC estejam no mesmo espaço físico da escola com seus pares, eles não estão participando das mesmas atividades, o que pode minimizar o potencial da Educação Física enquanto disciplina fomentadora do desenvolvimento de habilidades físicas e sociais desses indivíduos. Uma das sugestões dos adolescentes do presente estudo para promoção da participação na Educação Física é que o professor manifeste interesse e busque a adaptação das atividades propostas, de modo a torná-las adequadas para seu nível de habilidades.

A realização de adaptações que favoreçam a participação de alunos com PC requer que o professor tenha conhecimento acerca das habilidades e limitações individuais dos alunos, além de criatividade para modificar um jogo ou esporte mantendo seus elementos e regras fundamentais (HILDERLEY; RHIND, 2012). Ao mesmo tempo, é necessário que as demandas impostas pelas atividades adaptadas sejam ainda desafiadoras para os alunos com desenvolvimento normal, o que talvez constitua um dos maiores desafios (ALVES et al., 2017). Tais conhecimentos implicam que, durante sua formação, o professor de Educação Física tenha desenvolvido conhecimento para lidar com situações que exijam adaptações das 
atividades. No Brasil, somente a partir da década de 1990 disciplinas voltadas ao atendimento da pessoa com deficiência foram incorporadas na grade curricular dos cursos de graduação em Educação Física (CHICON, 2008). Dessa forma, é possível que muitos professores não tenham recebido formação que abordasse conteúdos relativos à atividade física adaptada e à inclusão (ALVES et al., 2017; CHICON, 2008). Uma evidência que embasa esse argumento é que o despreparo profissional e a falta de informação são razões apontadas por professores de Educação Física para justificar a dificuldade enfrentada na inclusão de alunos com deficiência (ALVES et al., 2017; GORGATTI; ROSE JÚNIOR, 2009).

No que se refere à influência do contexto físico na participação, o presente estudo revela uma situação na qual um potencial facilitador, o andador, na presença de um contexto inadequado (i.e., irregularidade do terreno), anula o papel facilitador do equipamento de suporte, resultando em interferência negativa no desempenho de adolescentes com PC. Tal situação destaca a interdependência entre os fatores físicos que influenciam a participação de alunos com PC nas aulas de Educação Física e sugere que potencializar essa participação requer uma visão abrangente, que envolva não somente a provisão de equipamento específico para mobilidade dos adolescentes, mas também a análise das características do ambiente no qual esse equipamento será utilizado (COPLEY; ZIVIANI, 2005).

Características do contexto pessoal também foram identificadas no presente estudo como elementos que impactaram a participação de adolescentes com PC na Educação Física. Por exemplo, alta percepção de autoeficácia e autoestima dos indivíduos parecem favorecer sua participação. Por outro lado, o sentimento de medo, introspecção, baixa percepção de autoeficácia e comparação das próprias habilidades com as dos colegas sem deficiência parecem comprometer a participação. Lauruschkus, Nordmark e Hallström (2014) afirmam que a experiência de sucesso no desempenho de atividades físicas alimenta o senso de competência de indivíduos com PC, facilitando o seu engajamento nessas atividades. Em contrapartida, a percepção de "não ser bom o suficiente" e a constatação das reduzidas chances de vencer em atividades competitivas afastam o desejo de crianças com PC de praticarem atividades físicas (LAURUSCHKUS; NORDMARK; HALLSTRÖM, 2014). Coates e Vickerman (2008) apontaram que crianças com deficiência frequentemente demonstram falta de confiança em suas habilidades e vergonha de suas limitações, quando reportam suas experiências durante as aulas de Educação Física. Como consequência, esses autores sugerem que o professor estabeleça metas alcançáveis por alunos com deficiência, para que eles aumentem a autoconfiança e sintam-se aptos para realizar as atividades propostas (COATES; VICKERMAN, 2008). Essa atitude do professor poderia romper com a propensão desses alunos de nutrirem sentimentos de frustração e desmotivação para o engajamento em atividades físicas.

O presente estudo apresenta algumas limitações. Os resultados apresentados elucidam fatores que influenciam a participação de adolescentes com PC na Educação Física sob a perspectiva dos próprios adolescentes, mas não esclarece a visão de outros atores do contexto escolar, como colegas, professores e mediadores. Futuros estudos que analisem a percepção combinada de todos os indivíduos envolvidos poderão ampliar a compreensão dos fatores que influenciam essa participação. Além disso, estudos futuros que agreguem dois ou mais métodos para coleta de dados, como, por exemplo, entrevista semiestruturada acrescida de observação, ou realização de grupos focais com os participantes do contexto escolar, poderão melhor esclarecer o intrincado processo de inclusão de adolescentes com PC nas aulas de Educação Física. 


\section{CONCLUSÃO}

A participação de adolescentes com PC nas aulas de Educação Física parece ser resultado de uma rede complexa de fatores que inclui elementos do contexto ambiental (i.e. atitudinal e físico) e pessoal. Conhecer sobre a influência desses fatores, sob a perspectiva dos próprios adolescentes, pode auxiliar profissionais da educação e reabilitação a entenderem essa realidade e a tomarem decisões efetivas no sentido de maximizar a participação. Os fatores apontados como facilitadores, como, por exemplo, atitudes de incentivo e amizade por parte de colegas, adaptação das atividades pelo professor, disponibilização de dispositivos de auxílio para marcha e alta percepção de auto eficácia do adolescente com PC, devem ser encorajados e ampliados. Por outro lado, os fatores que impõem barreiras à participação, como atitudes de indiferença e baixa receptividade por parte dos colegas, a falta de crença no potencial do aluno e a não adaptação das atividades pelo professor, a inadequação do espaço físico, bem como os sentimentos de medo e baixa percepção de auto eficácia do adolescente com PC, são elementos modificáveis e que necessitam de ações direcionadas para que possam ser superados. Ações educativas no ambiente escolar voltadas para a conscientização dos alunos sem deficiências acerca da importância da criação de um ambiente inclusivo, assim como a implementação de formação para o professor que aborde temas como a graduação da complexidade das atividades e análise do ambiente físico, consistem em possíveis intervenções com potencial para promoção da participação de adolescentes com PC na Educação Física Escolar.

\section{REFERÊNCIAS}

ALVES, Maria Luíza Tanure et al. Physical Education classes and inclusion of children with disability: Brazilian teachers'perspectives. Movimento, v.23, n.4, p.1229-1244, 2017.

BAILEY, Richard. Physical education and sport in schools: a review of benefits and outcomes. Journal of School Health, v.76, n.8, p.397-401, 2006.

BARBOSA FILHO, Valter Cordeiro; CAMPOS, Wagner de; LOPES, Adair da Silva. Epidemiology of physical inactivity, sedentary behaviors, and unhealthy eating habits among Brazilian adolescents: a systematic review. Ciência e Saúde Coletiva, v.19, n.1, p.173-193, 2014.

BARUFALDI, Laura Augusta et al. Meta-analysis of the prevalence of physical inactivity among Brazilian adolescents. Cadernos de Saúde Pública, v.28, n.6, p.1019-1032, 2012.

BIDDLE, Stuart; ASARE, Mavis. Physical activity and mental health in children and adolescents: a review of reviews. British Journal of Sports Medicine, v.45, p.886-895, 2011.

BRASIL. Lei Federal ํㅜ 9.394/96, de 20 de dezembro de 1996. Lei de Diretrizes e Bases da Educação. Diário Oficial da União, Brasília, DF, Seção 1, p. 27833. 23 dez. 1996.

BRASIL. Orientações curriculares para o ensino médio. Linguagens, códigos e suas tecnologias/Secretaria de Educação Básica. Ministério da Educação, Secretaria de Educação Básica, Brasília, v. 1, 2006. Disponível em: <http://portal.mec.gov.br/seb/arquivos/pdf/book volume 01 internet.pdf>. Acesso em: 21 jun. 2018. 
CARLON, Stacey et al. Differences in habitual physical activity levels of young people with cerebral palsy and their typically developing peers: a systematic review. Disability \& Rehabilitation, v.35, n.8, p.647-655, 2013.

CHICON, José Francisco. Inclusão e exclusão no contexto da Educação Física Escolar. Movimento, v.14, n.1, p.13-38, 2008.

CHICON, José Francisco; MENDES, Katiuscia Aparecida Moreira de Oliveira; SÁ, Maria das Graças Carvalho Silva de. Educação física e inclusão: a experiência na Escola Azul. Movimento, v.17, n.4, p.185-202, 2011.

COATES, Janine; VICKERMAN, Philip. Let the children have their say: children with special educational needs and their experiences of Physical Education: a review. Support for Learning, v.23, n.4, p.168-175, 2008.

COPLEY, Jodie; ZIVIANI, Jenny. Assistive technology assessment and planning for children with multiple disabilities in educational settings. British Journal of Occupational Therapy, v.68, n.12, p.559-566, 2005.

FONTANELLA, Bruno José Barcellos; RICAS, Janete; TURATO, Egberto Ribeiro. Amostragem por saturação em pesquisas qualitativas em saúde: contribuições teóricas. Cadernos de Saúde Pública, v.24, n.1, p.17-27, 2008.

FOWLER, Eileen et al. Promotion of physical fitness and prevention of secondary conditions for children with cerebral palsy: section on pediatrics research summit proceedings. Physical Therapy, v.87, n.11, p.1495-1510, 2007.

FRITZ, Jesper et al. A seven-year physical activity intervention for children increased gains in bone mass and muscle strength. Acta Paediatrica, v.105, n.10, p.1216-1224, 2016.

GORGATTI, Márcia Greguol; ROSE JÚNIOR, Dante de. Percepções dos professores quanto à inclusão de alunos com deficiência em aulas de Educação Física. Movimento, v.15, n.2, p.119-140, 2009.

HAGUETTE, Teresa Maria Frota. Metodologias qualitativas na sociologia. 10. ed. Petrópolis: Vozes, 2005.

HILDERLEY, Eleanor; RHIND, Daniel. Including children with cerebral palsy in mainstream physical education lessons: A case study of student and teacher experiences. Graduate Journal of Sport, Exercise \& Physical Education Research, v.1, p.1-15, 2012.

JANSSEN, Ian; LEBLANC, Alana. Systematic review of the health benefits of physical activity and fitness in school-aged children and youth. International Journal of Behavioral Nutrition and Physical Activity, v.7, n.40, p.1-16, 2010.

KAUFMAN, Alan; KAUFMAN, Nadeen. Kaufman Brief Intelligence Test. 2th.ed. San Antonio: Pearson Assessments, 2004.

KRIEMLER, Susi et al. Effect of school-based interventions on physical activity and fitness in children and adolescents: a review of reviews and systematic update. British Journal of Sports Medicine, v.45, n.11, p.923-930, 2011.

LAURUSCHKUS, Katarina; NORDMARK, Eva; HALLSTRÖM, Inger. "It's fun but..." Children with cerebral palsy and their experiences of participation in physical activities. Disability and

Rehabilitation, v.37, n.4, p.283-289, 2014. 
LAURUSCHKUS, Katarina et al. Physical activity in a total population of children and adolescents with cerebral palsy. Research in Developmental Disabilities, v.34, p.157-167, 2013.

LEHNHARD, Greice Rosso et al. A inclusão de alunos com deficiência em escolas públicas e em aulas de Educação Física: um diagnóstico. Lecturas: Educación Física y Deportes, v.14, n.139, 2009. Disponível em: <http://www. efdeportes.com/efd139/inclusao-de-alunos-com-deficienciaem-educacao-fisica.htm>. Acesso em: 7 ago. 2018.

LIMA, Francisco; SILVA, Fabiana Tavares dos Santos. Barreiras atitudinais: obstáculos à pessoa com deficiência na escola. In: SOUZA, Olga Solange Herval (Org.). Itinerários da inclusão escolar: múltiplos olhares, saberes e práticas. Canoas: ULBRA, 2009. p.23-32.

MASURIER, Guy Le; CORBIN, Charles. Top 10 reasons for quality physical education. Journal of Physical Education, Recreation and Dance, v.77, n.6, p.44-53, 2006.

NADEAU, Line; TESSIER, Réjean. Social adjustment of children with cerebral palsy in mainstream classes: peer perception. Developmental Medicine \& Child Neurology, v.48, n.5, p.331-336, 2006.

PALISANO, Robert et al. Development and reliability of a system to classify gross motor function in children with cerebral palsy. Developmental Medicine \& Child Neurology, v.39, n.4, p.214223, 1997.

PALISANO, Robert et al. Social and community participation of children and youth with cerebral palsy is associated with age and gross motor function classification. Physical Therapy, v.89, n.12, p.1304-1314, 2009

SILVA, Grazielle Roberta Freitas et al. Entrevista como técnica de pesquisa qualitativa. Online Brazilian Journal of Nursing, v.5, n.2, 2006. Disponível em: <http://www.objnursing.uff.br/index. php/nursing/article/view/382/88>. Acesso em: 7 ago. 2018.

THOMASON, Diane; SCHEPP, Karen. Psychometric characteristics of the Physical Education Activities Scale. Journal of Nursing Measurement, v.9, n.1, p.28-45, 2011.

UNESCO. Declaração de Salamanca sobre princípios, políticas e práticas na área das Necessidades Educativas Especiais. Salamanca, 1998. Disponível em: <http://unesdoc.unesco. org/images/0013/001393/139394por.pdf>. Acesso em: 21 jun. 2018. 


\section{Apoio:}

FAPEMIG, CNPq 